\title{
Olhares sociológicos sobre a ciência no século vinte: mudanças e continuidades
}

\author{
MARGELO FETZ \\ FABRÍCIO ANTONNIO DEFACG ${ }^{\text {s. }}$ \\ LERISSON NASGIMENTO"
}

\section{Resumo}

O artigo examina, em dois momentos distintos, as principais abordagens sociológicas sobre a ciência no século vinte: a Sociologia do Conhecimento, a Sociologia da Ciência e a Sociologia do Conhecimento Científico. No primeiro tópico são recapitulados os argumentos sociológicos de Karl Mannheim e de Robert King Merton. Defende-se a interpretação de que a obra de Mannheim seja reconhecida enquanto pressuposto epistemológico para o desenvolvimento da Sociologia da Ciência de Merton. Adaptada por Merton, a metateoria sociológica de Mannheim surge através de uma abordagem estrutural funcionalista associada a uma teoria de médio alcance. No segundo momento, são retomados os argumentos de Thomas Kuhn para, logo após, ser analisada a Sociologia do Conhecimento Científico enquanto apreciação construtiva da tradição de pensamento mertoniana. O estudo dos princípios lógicos da Sociologia do Conhecimento Científico de David Bloor e a investigação acerca da tradição de pensamento iniciada na Universi-

\footnotetext{
* Cientista Social e Mestre em Sociologia pela Universidade Federal de São Carlos (UFSCar). Doutorando em Sociologia pela Universidade Estadual de Campinas (UNICAMP).

** Cientista Social pela Universidade Estadual do Oeste do Paraná (UNIOESTE). Mestre em Ciências Sociais pela Universidade Federal de São Carlos (UFSCar). Graduando em Filosofia pela Universidade Federal de São Carlos (UFSCar). Doutorando em Sociologia pela Universidade Estadual Paulista Júlio de Mesquita Filho (UNESP/Araraquara).

*** Cientista Social pela Universidade do Estado do Rio Grande do Norte (UERN). Mestre em Ciências Sociais pela Universidade Federal de São Carlos (UFSCar). Doutorando em Sociologia pela Universidade Federal de São Carlos (UFSCar).
} 
dade de Edimburgo, na Escócia, foram o foco elementar dessa etapa do artigo. Finalmente, as principais características de cada uma das tradições são ressaltadas, buscando-se por mudanças e continuidades que viabilizaram o desenvolvimento da abordagem sociológica sobre a atividade científica desde sua gênese clássica até os estudos contemporâneos.

Palavras-chave: Epistemologia. Teoria sociológica. Sociologia do conhecimento. Sociologia da ciência. Sociologia do conhecimento científico.

\section{Introdução}

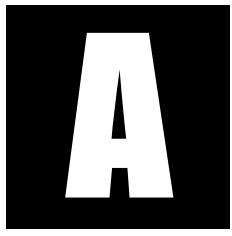

s inúmeras abordagens sobre a ciência através do horizonte sociológico revelam, em níveis distintos, a contribuição da sociologia para a consolidação de um campo investigativo capaz de descrever a atividade científica e o seu conhecimento de maneira mais específica e, ao mesmo tempo, questionar os direcionamentos da ciência em um cenário mais abrangente: a esfera social. Em um primeiro momento, encontramos uma tendência de aperfeiçoar cada vez mais os instrumentais metodológicos responsáveis pela apreensão direta da produção científica, em paralelo com as práticas estritas dos cientistas; num segundo momento, a Sociologia da Ciência se mostra interessada em pensar a relação entre a ciência e a sociedade, tanto no âmbito macro/global quanto na dimensão micro/local. Em linhas gerais, a Sociologia da Ciência é uma tentativa fecunda de abarcar a ciência não mais de maneira isolada, mas em sua necessária relação com os eventos externos que a circunscreve e que, em grande medida, condiciona as suas descobertas. 
O que hoje é concebido como um campo de atuação da Sociologia da Ciência é, também, o resultado de um desenrolar teórico lato que, sem dúvida, tem a sua base de fundamentação construída em aproximadamente um século de reflexões e de investigações distribuídas em diferentes propósitos e matrizes. Este fato transfigura-se em um elemento complicador para se pensar a área enquanto um campo unívoco de abordagens, mas, por outro lado, a tentativa de caracterizar uma continuidade no longo percurso das reflexões produzidas pode fornecer um norte para se entender, com maior clareza e profundidade, a sua situação atual. E é essa a tarefa que nos propomos a desenvolver neste artigo.

Pretende-se avaliar a Sociologia da Ciência em correspondência com os trabalhos desenvolvidos por Karl Mannheim, responsável pela confecção da Sociologia do Conhecimento na primeira metade do século XX. Seguido a isso, outro movimento teórico é indispensável para se perceber a sua constituição: trata-se da denúncia de que os condicionantes externos ao âmbito racional da produção científica têm um lugar privilegiado na configuração da lógica da descoberta científica, bem como na validação dos produtos da ciência. Esse ponto pode ser observado nos trabalhos de Thomas S. Kuhn e Robert K. Merton. ${ }^{1}$ Vale ressaltar que Merton pretendia desvendar o ethos social da atividade científica, colocando em segundo plano a lógica da descoberta de leis, axiomas e conceitos. No entanto, qualifica esse elemento como uma norma cognitiva. Diante deste quadro mais geral, acreditamos ser viável a avaliação das condições

1 Se para o primeiro a atividade científica corresponde inicialmente a um processo que lhe é alheio, caracterizado pela demarcação de um horizonte referencial prévio (paradigma), que permanece ou sofre alterações radicais em conformidade com os propósitos extra-teóricos dos agentes envolvidos na produção do conhecimento (comunidades científicas), em Merton a denúncia aparece com maior profundidade à medida que procura colocar a ciência em uma moldura social anteriormente estabelecida e, simultaneamente, responsável por encaixá-la nas determinações de uma instituição social. 
que possibilitaram o surgimento da Sociologia da Ciência, bem como a sua atual articulação no debate sociológico contemporâneo.

O caminho metodológico escolhido se justifica, pois a Sociologia do Conhecimento sistematizada por Mannheim, na dimensão teórica e metodológica, fornece, ainda hoje, o ponto de apoio para se investigar a ciência através do arcabouço conceitual da sociologia. Isto se deve, significativamente, ao fato de que Mannheim pretendia aprofundar o pressuposto a partir do qual a realidade social pode ser entendida como a esfera primeira de constituição do pensamento e, por conseguinte, de toda a atividade humana, que é, essencialmente, uma atividade socialmente condicionada. Não obstante, o esforço empreendido por Merton tornou a ciência um fenômeno palpável do ponto de vista sociológico ao desvendar as determinações de seu movimento como idênticas às demais instituições sociais, demonstrando em definitivo um processo de sociologização da ciência, desde sempre em construção. Acompanhando estes dois movimentos teóricos, o contexto histórico caracterizado pela desconfiança no conhecimento científico-tecnológico viabilizou a legitimação de um discurso sociológico sobre a ciência, o qual alterou substancialmente o domínio exercido por outras áreas do saber, em especial a Filosofia.

Deste percurso resultam reflexões teóricas e investigações empíricas com diferentes sentidos, que assumem a denominação de Sociologia da Ciência. Com uma pretensão distinta das abordagens anteriores, este novo modelo de investigação da ciência, pelo viés sociológico, tem sua origem no primeiro quartel do século XX e, apesar de hoje estar pulverizado em diferentes direções, há um elemento comum que atravessa as concepções iniciais: a radicalização da desconfiança tanto em relação à ciência como na emancipação humana através da razão. Da potencialização dessa desconfiança, gradativamente nascerá o interesse comum em desvendar a lógica que rege a atividade científica e, portanto, a ciência 
como um todo. A procura pela lógica da descoberta científica enquanto reflexo da sociedade, aparecerá em dois níveis, a saber, (1) focalizando o conhecimento científico por meio das técnicas e dos procedimentos utilizados em sua construção e (2) na sua articulação com outros sistemas discursivos que revestem a ciência das tendências sociais mais abrangentes e que, ao mesmo tempo, delimita o seu movimento dentro de um sistema regulatório, fornecido pela lógica do Mercado e do Estado.

Diante disso, o debate será iniciado com a análise da Sociologia do Conhecimento de Karl Mannheim, considerando-se os pressupostos fundamentais apresentados pelo autor, em especial a concepção de condicionamento do pensamento à esfera social. Tal pressuposto será aperfeiçoado por Robert Merton através de uma empreitada empírica que demonstrará, através da Sociologia da Ciência estrutural-funcionalista, a via de apreensão da ciência associada às regras que orientam as instituições sociais. O primeiro ponto deste trabalho, portanto, dedicar-se-á a pensar a ciência sob a ótica do universo social que a envolve e que a determina. Seguido a isso, no segundo ponto apresentaremos as transformações do discurso sociológico sobre a ciência a partir da segunda metade do século $X X$, tendo em vista o debate proposto pela nova sociologia da ciência, a Sociologia do Conhecimento Científico, caracterizada pela crítica ao pensamento de Robert K. Merton, pela radicalização da abordagem histórica de Thomas S. Kuhn e pela disseminação das concepções teóricoepistemológicas que norteiam esta área.

\section{A ciência sob o olhar sociológico: Karl Mannheim e Robert K. Merton}

A primeira forma de análise sistematizada sobre a ciência através da sociologia aparece no início do século XX, com a Sociologia do Conheci- 
mento desenvolvida por Karl Mannheim. Além de uma análise, esta área procura também repensar a própria epistemologia desenvolvida pela Teoria do Conhecimento na Modernidade Iluminista, tendo em vista a superação das demarcações rígidas impostas pela via das Ciências Naturais. Assim, se de um modo a Sociologia do Conhecimento contribui, no século XX, para a formação de um campo peculiar de abordagem da ciência, por outro lado, é também responsável pelo profundo afastamento dos referenciais positivistas desenvolvidos por Auguste Comte e por Émile Durkheim.

Partindo dessa constatação primeira, algumas indicações prévias são necessárias antes de vincularmos a Sociologia do Conhecimento ao surgimento da Sociologia da Ciência e as implicações destas duas áreas para a formação de uma nova forma de discurso sobre a ciência. Em primeiro lugar, a sistematização feita por Mannheim corresponde ao desdobramento de dois grandes referenciais teóricos construídos no século XIX: o marxismo e o historicismo hermenêutico. Em segundo lugar, a Sociologia do Conhecimento precisa ser entendida em conformidade com o anseio de orientação das transformações sociais, o que implica na formulação de uma epistemologia comprometida com a sociedade, ou, de modo conceitual, que apresente uma função social para a ciência.

Em se tratando do horizonte de referência retirado por Mannheim do marxismo, o pressuposto da Sociologia do Conhecimento é preenchido pela afirmação do condicionamento social do pensamento. O pensamento se dá, em especial no caso do pensamento científico, determinado pelo contorno social, inerente a uma temporalidade e a uma espacialidade delimitadas. Tal pressuposto é importado da noção de ideologia apresentada por Marx e Engels (2007a). Segundo Mannheim (1976), a noção de ideologia significa, antes mesmo de suas conseqüências políticas, o fato de que o pensamento aparece sempre pré-determinado pelos interesses de um grupo dentro da esfera social. Mannheim descarta a possibilidade de existir uma verdade histórica capaz de se sobrepor às manifestações 
ideacionais que emergem do jogo de interesses que forma na sociedade um campo de disputa. Toda forma de pensamento que emana do tecido social fragmentado pelas disputas dos grupos é, em parte, desde sempre ideológico, pois tenta impor sua condição social através da expansão dos seus respectivos interesses.

Diante da estratificação social apresentada pelo marxismo, que entende a sociedade como constituída por duas classes em conflito - no caso da modernidade, burgueses e proletários (MARX e ENGELS, 2007b) -, a perspectiva teórica que funda a Sociologia do Conhecimento concebe a sociedade como o resultado da combinação de inúmeros grupos sociais, os quais apresentam um pensamento diferenciado, de acordo com o lugar ocupado na própria sociedade. Entretanto, um véu de universalidade recobre a pluralidade social em termos do pensamento socialmente condicionado, sendo este o ponto de acesso às determinações de uma época como um todo (Weltanschauung).

Distanciando-se do marxismo, Mannheim vai buscar no historicismo hermenêutico fundado por Dilthey um modo de interpretar a formação da sociedade e, ao mesmo tempo, um suporte para a elaboração da Sociologia do Conhecimento. O norte do pensamento de Dilthey (1986) é idéia de que a história não possui um fio condutor inexorável; sem um elemento teleológico, base para a defesa do proletariado como portador de uma "verdade histórica", no caso do marxismo, resta pensar a história em constante construção. O homem, por sua vez, está inserido no fluxo histórico e é, simultaneamente, seu construtor e produto dele, caracterizando-se neste processo como uma unidade psicofísica de vida. Por conseguinte, a primeira derivação desta concepção de Dilthey é a de que não se pode mais conceber a história em seu sentido universal, mas nem por isso o horizonte histórico se dá completamente pulverizado. No meio do caminho entre o máximo de universalidade e o máximo de particularidade, a história é pensada como um movimento orientado por um 
elemento abrangente que é submetido ao seu próprio processo, sendo, portanto, reordenada entre uma época e outra.

Tanto o marxismo, ao fornecer uma base material/social para o pensamento, quanto o historicismo, ao retirar a possibilidade de determinismo da história, tornam-se influências centrais para a Sociologia do Conhecimento. Em seu desenvolvimento posterior, tal área passa a entender a realidade social como a expressão do pensamento, ao passo que este pensamento é expressão dos contornos sociais, demarcando assim seu viés hermenêutico pela negação de qualquer causalidade possível e a consequente afirmação da realidade multideterminada. Este ponto de partida é enfatizado por Mannheim em Ideologia e Utopia, texto de 1929, onde o autor se propõe a tarefa de entender como os grupos sociais se comportam em função do pensamento enquanto cosmovisão que nortearia a sua atuação no mundo. Em vista disso, o pensamento socialmente condicionado pode se apresentar de dois modos fortemente distintos e, por vezes, altamente antagônicos: (1) uma representação ideológica da realidade social que tem por finalidade a manutenção da situação vigente ou (2) uma inadequação com as condições sociais vigentes que produz, no âmbito do pensamento, uma textura utópica/desiderativa como caminho para a superação e, por certo, para o aniquilamento das formas ideológicas. Em resumo, para Mannheim o conflito social, apreendido por meio da Sociologia do Conhecimento, é também seu próprio ponto de sustentação, onde a expressão da cultura se faz presente como uma forma delimitada de pensamento (ideológico ou utópico), mesmo que nem sempre seja fácil separar com total segurança uma de outra dentro do movimento social.

Decorre deste percurso inicial o fato de que a Sociologia do Conhecimento, ao se aproximar do movimento social na sua forma de representações ideacionais (mentalidades), é também expressão da cultura. Em outras palavras, a fundamentação epistemológica das Ciências Sociais, a partir da perspectiva mannheimiana, acontece quando a cientificidade é 
balizada pelo movimento social, distanciando-se, assim, da postura positivista envolvida na pretensão de "isolacionismo" da realidade social: ciência e realidade, no caso da Sociologia do Conhecimento, permanecem na mesma dimensão; e considerando as alterações significativas no modo como o pensamento se dispõe na sociedade, a ciência sofre também mudanças em seu posicionamento.

Em vista desta aproximação da ciência com as formas de pensamento constituídas dentro da esfera social, a Sociologia do Conhecimento assume outro desdobramento: a função social. Podemos, diante destes dois processos que fundam a Sociologia do Conhecimento (espaço epistemológico e capacidade de atuação social), pensá-la como essencialmente normativa. Tal normatividade, que procura regular o movimento social através do Planejamento Democrático, é o ponto de validação da cientificidade desta área, a qual, conforme insiste Mannheim, não poderia alcançar legitimidade se permanecesse alheia às transformações sociais. No entanto, é possível afirmar que este segundo aspecto apresenta uma separação cronológica em relação ao primeiro. ${ }^{2}$

Em termos do contexto do período, a proposta mannheimiana torna-se mais compreensível. O ambiente tenso na Alemanha, ocasionado em grande parte pela esperança do povo alemão na chegada do III Reich e, com ele, o fim das turbulências e crises, demonstrou, em sua realização, a fragilidade do projeto republicano moderno diante do problema das massas e da violência desmedida, mediada pelo descontrole do poder político nas mãos do Esta-

2 Na década de 1920, Mannheim estava vinculado ao debate filosófico do período e, com isso, sua principal preocupação foi a de estabelecer um campo epistemológico de apreensão da realidade social distante do modelo "naturalizante" do pensamento moderno. O texto de 1929 (Ideologia e Utopia) marca a passagem da perspectiva do autor, no sentido de aplicar os produtos da reflexão anterior na forma de intervenção social. Apesar de colocar como subtítulo da obra "uma introdução a Sociologia do Conhecimento", seu alcance é muito maior: pela primeira vez o autor tenta sistematizar a noção de intelligentsia e sua possibilidade de intervenção social, o que implica em considerar a atuação normativa da Sociologia do Conhecimento como sendo parte de sua fundamentação. 
do/Nação. A confiança e a responsabilidade depositada por Mannheim no intelectual é uma resposta ao seu tempo; uma resposta que assume a via do controle social, priorizando a propaganda e a educação como mecanismos para contornar a incerteza em uma sociedade que vivencia o esvaziamento dos valores e da cultura inerentes ao processo civilizatório.

É em vista disso que a Sociologia do Conhecimento se diferencia substancialmente da Sociologia da Ciência na contemporaneidade: a busca pela normatização do processo social, mesmo sem uma teleologia definida a priori. O planejamento democrático tem, neste caso, um vínculo indispensável com o projeto mais amplo da Sociologia do Conhecimento, na sua fundamentação elaborada por Mannheim. Trata-se de desenvolver mecanismos de controle/intervenção sob um processo social descontrolado; mas, para isso, o primeiro passo é a compreensão do processo social. Assim, na primeira formulação (antes de Ideologia e Utopia), a Sociologia do Conhecimento tem um compromisso epistemológico, norteado pelo anseio de sustentar as Ciências Sociais diante do modelo das Ciências Naturais. Com a composição de Ideologia e Utopia, a concepção mannheimiana passa para o aspecto político e militante.

A pretensão de abordar a gênese da Sociologia da Ciência através da Sociologia do Conhecimento é uma inserção na fase epistemológica desta última, uma vez que nela está o pressuposto da determinação social do pensamento. No entanto, este pressuposto foi depurado por outras reflexões, antes de caracterizar a Sociologia da Ciência como se apresenta na contemporaneidade ${ }^{3}$. Entre tais reflexões, destaca-se o trabalho do sociólogo Robert K. Merton, que procurou avaliar o ethos social da ciência,

3 Antes de que seja iniciada a segunda etapa desse debate, faz-se necessário recordar ao leitor um importante elemento, uma ressalva metodológica que, apesar de curta, é de significativa relevância. É irreal pensarmos de uma maneira linear a passagem da sociologia do conhecimento à sociologia da ciência. No entanto, esse caminho apresenta-se como uma abordagem viável para a organização de nosso raciocínio. Pretende-se deixar claro ao leitor, portanto, de que se trata de um tratamento analítico arbitrário, porém necessário. 
tomando como ponto de partida o fato de que a instituição científica possui regras e normas socialmente convencionadas e responde à dinâmica social como qualquer outra instituição social.

A origem da Sociologia da Ciência é circunscrita ao ambiente intelectual norte-americano da década de 1930, quando poucos trabalhos foram redigidos. Entre as pesquisas com maior impacto no campo acadêmico, podemos citar a tese de doutorado de Merton (1970a), originalmente publicada no ano de 1938. Esquecida por quase dez anos (na década de 1940), ela voltou a ganhar força nos anos cinquenta, fortalecendo-se no período seguinte. Seu desenvolvimento está diretamente associado à figura intelectual de Merton. Merton soube empregar, como poucos o fizeram, as mais diferentes abordagens da sociologia clássica para lidar com o estudo da realidade empírica. De qualquer forma, podemos falar em circunstâncias singulares norte-americanas, nas quais foi possível o desenvolvimento de um estilo de pensamento coerente com o espírito da época, ou seja, a sociologia, historicamente contextualizada, trará em seu bojo as singularidades de seu tempo. ${ }^{4}$ Recapitular o ambiente intelectual norte americano talvez possa nos auxiliar no processo de compreensão das mudanças sociais pelas quais a sociologia do conhecimento passou, ligando-se à sociologia da cultura de massas e, no pensamento de Merton, dando origem à sociologia da ciência, interpenetrada pelo funcional estruturalismo.

Paralelo aos pilares teóricos da Sociologia do Conhecimento de Karl Mannheim, a Sociologia da Ciência obteve elementos novos e essenciais para o seu desenvolvimento no círculo acadêmico norte americano. Merton não foi o primeiro a empregá-la, tendo-a recebido de seus mes-

4 Utilizamos a concepção teórico-epistemológica de Karl Mannheim para o estudo da sociologia da ciência de Robert Merton - nesse sentido, o estudo da estrutura interna de seu pensamento correlacionar-se-á com o universo sócio-histórico de sua época. A coerência interna da obra, portanto, deverá ser historicamente situada. 
tres e do ambiente acadêmico com um todo. Muito da sua recepção por esse intelectual deve-se à sua trajetória teórica de pensamento. Embora esse fato seja de suma importância para estudarmos o pensamento de Merton enquanto unidade individual, dever-se-á refletir sobre o pessimismo que pairava sobre o ambiente intelectual local, assim como ocorrido com o ambiente alemão 5 . Nas palavras de Merton:

O pensamento norte-americano se revelou receptivo para a sociologia do conhecimento, em grande parte porque esta disciplina trata de problemas, conceitos e teorias que são cada vez mais pertinentes à situação social contemporânea dos Estados Unidos, porque a sociedade norte-americana chegou a ter certas características das sociedades européias nas quais surgiu inicialmente a disciplina (MERTON, 1970b, p. 554).

Embora seja o pensamento de Karl Mannheim de vital importância, quando Merton se refere à sociologia do conhecimento ele não o faz restritamente à tradição da Wissenssoziologie, mas a partir de um leque mais amplo de autores. Além do próprio Mannheim, Merton ventila as concepções teóricas de Karl Marx, Max Scheler, Émile Durkheim e Pitirim Sorokin. Além desses, diretamente citados em sua obra, podemos acrescentar ainda as concepções de Max Weber, Georges Gurvitch e Talcott Parsons, sendo este último seu mestre durante o doutorado na Universida-

5 Se o contexto alemão era marcado pelo desastre da primeira guerra, pelas restrições do tratado de Versalhes e pela ascensão do nazi-fascismo na Alemanha, trazendo à tona todos os fantasmas históricos daquela sociedade, o ambiente americano não era diferente. Apesar da euforia do capitalismo de massas dos anos de 1910 e 1920, a guerra marcaria parte de seu ambiente intelectual, não de fato mas, principalmente, pela imigração de inúmeros pensadores europeus que a vivenciaram pessoalmente. É o caso do próprio Mannheim e de outros como Theodor Adorno, cujas relações pessoais com Paul Lazarsfeld, sociólogo vienense, demonstraram o choque entre duas diferentes tradições de pensamento (JAY, 1986). Assim como o ambiente intelectual europeu, berço da sociologia do conhecimento, a academia norteamericana também vivenciava um pouco de seu pessimismo. Na realidade, grande parte do pessimismo europeu somente se realizou no interior da academia norte-americana. 
de de Harvard. Apesar das contribuições de alguns desses autores serem esparsas, Merton dá a seguinte definição à sociologia do conhecimento: um ponto central de concordância em todos os enfoques da sociologia do conhecimento é a tese de que o pensamento tem uma base existencial na medida em que não é determinado imanentemente e enquanto um ou outro de seus aspectos pode ser derivado de fatores extracognoscitivos (MERTON, 1970b, p. 559). É dessa premissa teórica que derivará a Sociologia da Ciência, subdisciplina da Sociologia do Conhecimento. Ao ser sistematizada por Merton, essa nova subdisciplina ganha uma modelação diferenciada se comparada unicamente aos preceitos teóricos da Sociologia do Conhecimento de Mannheim. E isso se deve, em grande parte, ao fato de que Merton não foi somente um bom analista da realidade empírica, mas também um importante teórico das Ciências Sociais. Seu pensamento é classificado como representante da tradição funcional-estruturalista. Sua ligação com a tradição durkheiminiana é, portanto, clara. Mas, como relata Piotr Sztompka (1996), Merton apresentava uma forte personalidade, o que o tornava um intelectual singular, sobretudo por sua capacidade de saber relacionar diferentes pressupostos teóricos.

O debate teórico proposto por Merton revela uma importante oposição para refletirmos a passagem da Sociologia do Conhecimento para a Sociologia da Ciência. Sua concepção acerca das Ciências Sociais é muito clara: a Sociologia é uma ciência jovem e, como tal, não goza de um discurso que possa ser generalizado para todos os fenômenos sociais. Em vista disso, as ciências sociais devem ser sustentadas por uma teoria de médio alcance, opondo-se ao chamado sistema total de teoria sociológica - a referência máxima para esse discurso meta-teórico, ao qual se opõe Merton, era por ele muito conhecido: os procedimentos adotados por Talcott Parsons (1951). 
De outro modo, Teoria sociológica se refere a conjuntos de oposições logicamente entrelaçados dos quais se podem derivar umas quantas uniformidades empíricas (MERTON, 1970b, p.51). Enquanto que a teoria de médio alcance é caracterizada por meio de

hipóteses necessárias de trabalho que surgem em abundância durante a rotina de pesquisas diárias e amplos esforços para desenvolver uma teoria unificada capaz de explicar todas as uniformidades observadas de comportamento, organização e mudanças sociais. [...] A teoria de médio alcance é usada principalmente para servir de guia às pesquisas empíricas. Ocupa uma situação intermediária entre as teorias gerais de sistemas sociais, as quais estão muito afastadas das espécies particulares de comportamento, organização e mudança sociais para explicar o que é observado, e as minuciosas ordenadas descrições de pormenores que não estão de modo algum generalizados. [...] As teorias de médio alcance tratam de aspectos limitados dos fenômenos sociais, conforme o próprio nome indica. Fala-se de uma teoria de grupos de referência, de mobilidade social, de conflitos de desempenho de papéis e de formação de normas sociais, exatamente como se se falasse de uma teoria de preços, uma teoria dos germes das doenças ou uma teoria cinética dos gases (MERTON, 1970b, p. 51-2).

Com relação aos sistemas totais, Merton afirma que: o primeiro equívoco é o de pensar que os sistemas de pensamento possam desenvolver-se eficazmente, antes que uma quantidade de observações básicas tenha sido acumulada. Dando continuidade a sua argumentação, lembra Merton que a segunda concepção errônea [...] repousa numa falsa suposição de contemporaneidade histórica, segundo a qual todos os produtos culturais existentes no mesmo momento histórico possuem o mesmo grau de maturidade (MERTON, 1970b, p.59). Ao tratar do complexo teórico de autores imbuídos do sprit de système, como Comte e Spencer, surge à tona a distinção entre Ciências Naturais e Ciências Sociais e a ques- 
tão da adaptação direta do sistema de análise positivo para um universo histórico-cultural. Nesse ponto, observa-se que a obra de Merton não toma a estática dos fenômenos sociais como um elemento fundamental. O estrutural-funcionalismo mertoniano, portanto, é atravessado por certo dinamismo, o que desmente as teses críticas que afirmam a incapacidade do funcionalismo de Merton para explicar a mudança social; a mudança seria possível e poderá ser explicada, mas sob o canon da noção de função social. Nesse contexto, não é a explicação que conta, mas, sim, como ela é trabalhada teórica e epistemologicamente pelo intelectual.

A oposição entre metateoria e teoria de médio alcance fomenta uma importante oposição analítica na obra de Merton. É a partir desse enfoque que os fundamentos teóricos da Sociologia do Conhecimento de Karl Mannheim são ressemantizados por Merton, dando origem a uma Sociologia da Ciência pouco interessada em responder algumas das questões canônicas entre os aspectos sócioexistenciais da indeterminação imanente e dos aspectos extra-cognoscitivos que interpenetrariam a relação entre ciência e sociedade. Merton, diferentemente dos intelectuais do século XIX e do próprio Mannheim, em grande medida, não se preocupa com tais questões, não porque elas não existam, mas porque não se possui, ainda, um rol de conhecimentos sociológicos que possa servir de base para a reflexão acerca de elementos tão gerais, do ponto de vista da teoria social.

A sociologia do conhecimento de Karl Mannheim, assim, é um importante pilar para o pensamento social que toma a ciência enquanto um objeto socialmente condicionado. No entanto, essa passagem do pensamento socialmente condicionado ao condicionamento empírico dos fenômenos científicos, para Merton, é de extrema complicação. Antes de poder elaborar uma teoria total, que fundamente teoricamente o condicionamento social do pensamento, é necessária a criação de uma teoria de médio alcance que canalize o estudo de variáveis que, por sua 
vez, fundamentem empiricamente a relação entre ciência e sociedade. Sendo assim, Merton, próximo da tradição de pensamento funcionalista das Ciências Sociais, volta-se para o estudo de problemas básicos, dando solução ao primeiro equívoco dos tratados metateóricos. O primeiro objetivo seria acumular uma quantidade de observações básicas de caráter empírico acerca da estrutura da ciência enquanto uma instituição social para, então, futuramente talvez, possibilitar o desenvolvimento de estudos de caráter macro-social com alto grau de generalização.

Se, para Mannheim, os condicionantes sociais do pensamento são entendidos enquanto pressupostos da análise sobre a epistemologia, Merton busca operacionalizá-la empiricamente. Em outras palavras, Merton reduz o escopo do enfoque teórico proposto por Mannheim, subdividindo-o em elementos de pequeno porte, passíveis de tratamento particular. O pensamento em geral, dessa forma, encontrar-se-ia no plano metateórico da gnosis - impossível, ou pelo menos pouco mensurável a ponto de ser abordado por uma ciência tão jovem, como é o caso da sociologia. Merton, portanto, opera um recorte sob a concepção totalizante de Mannheim, deslocando a esfera da gnosis para a da epistême da ciência, tomando-a enquanto locus elementar de elaboração de conhecimentos. Embora o recorte elaborado por Merton privilegie a interpenetração do universo social com o científico (e esse é o fundamento teórico que possibilita o tratamento da ciência enquanto um fenômeno sociológico), o desenvolvimento analítico de sua obra contemplou o ethos da atividade, deixando de lado a pretensão sistêmica de relacionar diretamente um mundo objetivo e neutro a outro, subjetivo e historicamente contingenciado.

Diante disso, podemos concluir que a unidade empírica da Sociologia da Ciência estrutural-funcionalista é a ciência enquanto instituição social - ou uma subdivisão da categoria pensamento, empiricamente operacionalizada. Seu fundamento teórico é revelado através do fato de que 
o pensamento possuiria uma base existencial que, depurada pela construção teórica de Merton, atingiria a estrutura da organização científica enquanto um elemento sociológico. Logo, do mesmo modo que as teorias de médio alcance tratam de aspectos limitados dos fenômenos sociais, analisa-se a instituição científica a partir de suas formas organizacionais, como que se essa estivesse, inicialmente, deslocada do ambiente social exterior. De outra forma, a Sociologia da Ciência trata dos fenômenos sociais empíricos característicos da organização interna da instituição científica. Se o condicionamento social do pensamento é algo importante, mas difícil de ser demonstrado, a Sociologia da Ciência funcional-estruturalista circunscreve os aspectos limitados da porosidade entre sociedade e ciência que poderiam ser empiricamente demonstrados, mas que correriam o risco de ser sociologicamente irrelevantes. Esse foi o principal risco enfrentado, de maneira consciente, por Merton durante toda a sua obra.

A ciência, portanto, tende a apresentar um ordenamento objetivo de funcionamento, cujos padrões de reprodução são compreendidos como normas sociais de regulação das atividades e de comportamentos. Logo, é possível elaborar um tipo ideal de ciência, cujo funcionamento pleno fundamenta e caracteriza as relações de oposição e de conflito entre norma, função, anomia e desvio (MANNHEIM; MERTON; MILLS, 1974). Pensase na noção de equilíbrio interno entre os fenômenos sociais. A categoria equilíbrio liga-se diretamente à noção de igualdade entre os participantes, em que todos apresentariam as mesmas condições de trabalho. $\mathrm{O}$ desvio, portanto, acarretaria em uma forma indesejada de desequilíbrio funcional, cuja correção levará, necessariamente, a um novo estado de equilíbrio entre as formas estruturais e particulares. Dada essa concepção de organização institucional, foi possível para Merton caracterizar os elementos que trabalham para a manutenção funcional da organização institucional e aqueles que trabalham para a ruptura dos padrões sociais 
de normalidade, vistos como maléficos à boa produção de conhecimentos universais. ${ }^{6}$ Se a norma padrão de comportamento interno implica na realização da função da instituição científica, a principal questão a ser respondida pela tradição de pensamento estrutural-funcionalista é de como essa instituição se organiza com o objetivo de cumprir a sua função de produção de um tipo singular de conhecimento.

Finalmente, a metáfora aqui utilizada é a de um organismo biológico, onde as partes se relacionam com o todo em prol de sua manutenção sistêmica, isto é, a ciência composta por elementos que tenderiam a um estado normal de equilíbrio, onde o prestígio social e a qualidade do trabalho se interpenetrariam ao mesmo tempo em que forneceriam ao cientista a motivação para que produção científica seja elaborada, respeitando-se as normas sociais e as normas cognitivas, fundamental para que as pesquisas obtenham o reconhecimento por seus pares. ${ }^{7}$ Disso deriva o fato de que a ciência pôde se tornar um objeto de pesquisa sociológico por apresentar, de maneira geral, quatro imperativos: (1) o comunismo; (2) o universalismo; (3) o desinteresse e (4) o ceticismo. Tais imperativos demonstrariam a sociologização da ciência sob o molde de uma instituição social, respondendo aos valores e normas padrões de uma comunidade científica.

\footnotetext{
6 De maneira geral, trata-se do mesmo sentido de ideologia e utopia. O léxico é modificado, mas o sentido é o mesmo, circunscrito ao ambiente da instituição científica e de uma comunidade de cientistas.

7 Prestígio social e reconhecimento pelos pares compõem o léxico analítico de outro importante viés sociológico. Estamos falando de Pierre Bourdieu (2001), que apesar das desavenças intelectuais com Merton, reconheceu em um de seus trabalhos sobre a dinâmica social do campo científico a importância da contribuição das pesquisas empíricas de Merton para o desenvolvimento da sociologia da ciência.
} 


\section{Entre a Sociologia da Ciência e a Sociologia do Conhecimento Científico}

O olhar sociológico sobre a ciência apresenta, atualmente, alterações significativas. Podemos defender a tese de que os estudos sociológicos sobre a ciência passaram por um processo de pulverização, sob o qual a tradição de pensamento que surgiu, em grande medida, com Karl Mannheim, e que inspirou fortemente os trabalhos de Robert K. Merton disseminou-se pela academia de forma assaz distinta. Não é possível, atualmente, visualizar uma unidade epistemológica elementar, dado que o núcleo teórico da disciplina, amiúde, está cada vez mais próximo da multidisciplinaridade. Do ponto de vista histórico, três tradições teoricamente diferenciadas podem ser identificadas, sendo que as duas primeiras linhas de pensamento possuem fundamentos claramente observáveis, como já foi demonstrado no ponto anterior. Com relação àquilo que aqui chamamos de terceira tradição, encontramos apenas um esboço de orientação para o desenvolvimento de um pensamento analítico, compreensivo e explicativo.

Ademais, a terceira tradição de pensamento distingue-se qualitativamente das duas anteriores em vários sentidos, caracterizando-se, particularmente, por certo ecletismo teórico-metodológico, sendo difícil a sua qualificação sob um núcleo explicativo/compreensivo unívoco. Temos, assim, a seguinte trajetória: i) a Sociologia do Conhecimento (SCo); ii) a Sociologia da Ciência (SCi); iii) a Sociologia do Conhecimento Científico (SCCi). A SCCi apresenta outras denominações como, por exemplo, nova sociologia da ciência ou terceira onda dos estudos científicos. A passagem de uma tradição à outra, de certa forma, marca um processo de radicalização do pessimismo sobre a atividade científica e à razão. Mesmo o conceito de sujeito epistêmico, tanto nas Ciências Sociais quanto nas Ciências Naturais, vem sendo gradativamente destituído dos pressupostos clássicos de imparcialidade, objetividade e neutralidade. Assim, a noção 
de verdade científica emerge associada cada vez mais à esfera do poder social e à ideologia política. A metáfora tomada para a representação da atividade científica é a guerra, enquanto atividade de caráter bélico. Outra forma empregada para a caracterização do universo científico é a noção de negociação, a partir da qual a compreensão da ciência realizase pela observação da organização em redes sociais - mesmo sob a forma de redes epistemológicas ou de arenas trans-epistêmicas.

$\mathrm{Na} \mathrm{SCCi}$, diferentemente da tradição estrutural-funcionalista, o conhecimento é o fenômeno fundamental a ser problematizado, sendo essa a principal crítica feita por essa tradição à anterior, justificando-se, assim, a adoção de um novo paradigma interpretativo para a atividade científica. O foco principal é a ciência em construção, e não apenas a dinâmica entre os pares no interior da comunidade científica, suas normas sociais e cognitivas, bem como os seus padrões de sociabilidade. Nesta perspectiva, o laboratório surge como espaço privilegiado para o estudo da dinâmica científica: é o local onde ocorre a produção do conhecimento, onde as caixas pretas encontrar-se-iam ainda abertas, ou em processo de fechamento. Para além do laboratório e de sua dinâmica social, analisam-se as controvérsias científicas, suas soluções. Nesse sentido, a distinção entre o falso e o verdadeiro se dá sob um viés estritamente social. Não se fala apenas nas formas de produção do conhecimento, mas no conhecimento científico enquanto uma construção contingencial da sociedade, como produto do tempo e do espaço sociais. O debate metodológico e teórico é colocado em segundo plano - e, por vezes, desconsiderado -, sendo que os elementos extracognitivos, nesse sentido, não seriam interpretados como fatores externos à atividade científica, mas, sim, enquanto elementos fundamentais que a compõem, que a configuram em sua forma constitucional, institucional e, sobretudo, epistemológica. Uma passagem, no entanto, é capital para a depuração da SCi em SCCi, a qual caracteriza a 
transição entre as duas concepções. Falamos do importante trabalho de Thomas S. Kuhn sobre a estrutura das revoluções científicas.

A exposição feita por Kuhn (2006) trata de como o empreendimento científico pode ser compreendido sócio-historicamente, em contraposição a uma interpretação que vê a ciência como uma esfera que produz conhecimento apenas obedecendo às regras do método científico racional. No prefácio de A Estrutura das Revoluções Científicas, Kuhn afirma que foi bastante influenciado pelas idéias do médico polonês Ludwik Fleck (1986). ${ }^{8}$ Assim como este, Kuhn não crê que a ciência apresenta um desenvolvimento de caráter contínuo e cumulativo. A ciência progrediria

8 Menção deve ser feita aqui ao trabalho de Ludwik Fleck (1986), médico polonês especializado em bacteriologia e sorologia. Fleck faz uma análise histórica do desenvolvimento da sífilis, tomando-a como um fato científico socialmente construído. Seus estudos no campo da medicina the proporcionaram o ponto de partida para a tese sobre como os mecanismos sociais "dirigem" e "constroem" os fatos científicos. Isso em muito se deve à singularidade da atividade médica que, de acordo com o autor, apresenta um empreendimento científico de caráter coletivo e voltado para o atendimento de necessidades sociais, sob a égide da instrumentação e da eficiência. Ludwik Fleck identificou duas particularidades nesse campo: a) o conhecimento na medicina não está direcionado para o que é regular, e sim para o anormal, o patológico (os estados de enfermidade), por isso analisa-se sempre cada caso, assim conceitualizações em medicina são de tipo menos "abstrato" e mais de tipo estatístico; b) não se desenvolve um conhecimento por si mesmo, este só ocorre mediante avaliações de êxito. Não há essência, portanto, em um fenômeno científico no campo da medicina, pois as noções de patológico e anormal apresentam contingências espaço-temporais que as circunscrevem em um plano subjetivo, socialmente determinado, atribuindo um valor extra-científico à produção de discursos classificatórios. Interessa-se pelas estruturas sociais (mecanismos "externos" à ciência) e de pensamento que levam às práticas de caráter científico. Por isso procura desenvolver uma teoria do estilo de pensamento e do coletivo de pensamento. Coletivos de pensamento - unidade social da comunidade de cientistas de um determinado campo, como no caso dos profissionais de saúde, por exemplo - que possuem estilos de pensamento - pressuposições de estilo sobre os quais o coletivo constrói seu edifício teórico - isso variando conforme o grupo. Nesse sentido, o progresso do conhecimento significa um desenvolvimento coletivo incessante do estilo de pensamento. Este último possui três etapas: i) instauração do estilo de pensamento; ii) extensão do estilo de pensamento; ii) transformação do estilo de pensamento. $\mathrm{O}$ desenvolvimento do conhecimento científico não é cumulativo, é fruto de uma reorganização produzida no processo de investigação, pois as idéias surgem da circulação do pensamento em um ambiente coletivo de cientistas. 
nos momentos de crises paradigmáticas. O desenvolvimento da ciência apresentaria estágios pré-paradigmáticos, paradigmáticos (ciência normal) e períodos de crise/revolução onde o paradigma é colocado em cheque. O paradigma é um modelo ou um padrão socialmente aceito pelas comunidades científicas. Assim como uma decisão judicial é aceita no direito costumeiro, o paradigma é um objeto a ser melhor articulado e precisado em condições novas ou de maior rigor científico.

A existência de um paradigma coloca um problema a ser resolvido pelos demais cientistas na prática da ciência normal. O trabalho do cientista é o de montar quebra-cabeças; o resultado, já se sabe, é o paradigma, uma resposta, uma explicação para um determinado fenômeno científico. O fascínio do cientista na ciência normal, no período paradigmático, é o de descobrir melhores formas de se montar o mesmo quebra-cabeça. Nesse universo, a comunidade científica desempenha um papel de suma importância. Os paradigmas delimitam o que é passível de tratamento científico. Os paradigmas assumem, por vezes, a forma de tradições sociais inseridas no contexto de pesquisa, condicionando a prática científica. A ciência normal se constitui como um conjunto de procedimentos reconhecidamente aceitos. Às revoluções paradigmáticas, que se caracterizam pela quebra da unidade epistemológica reconhecida pelos pares, sucedem-se, quase simultaneamente, à passagem das gerações de cientistas.

A história das revoluções paradigmáticas é, portanto, a história dos homens que se encontram por detrás delas, bem como das características societárias que fundamentaram a possibilidade da mudança social. Somente o desenrolar histórico seria capaz de demonstrar a fundamentação social das leis científicas - haveria, assim, uma perfeita correspondência entre os fundamentos empíricos e teóricos da explicação científica e os fatores subjetivos e extra-cognitivos, condizentes com o universo social. Uma revolução científica que falsifique os fundamentos da ciência normal 
somente é possível quando se encontra diretamente associada a algum tipo de mudança social. Finalmente, a produção dos fatos científicos não pode ser compreendida apenas a partir da relação sujeito - objeto, mas através da relação sujeito-sujeito. Em outras palavras, o olhar do observador é condicionado pelo olhar da comunidade científica, onde ambos são condicionados pelo paradigma, também chamado de matriz disciplinar.

A SCCi, nesse sentido, busca dar fundamentação epistemológica ao debate proposto por Kuhn. Ao viés histórico e processual de Kuhn, a SCCi tenta atribuir fixidez, através do acréscimo de um novo pressuposto teórico-normativo, capaz de re-orientar a interpretação da ciência e do tipo de conhecimento produzido em seu ambiente social. A neutralidade axiológica é deixada de lado, não sendo, portanto, mais do que um elemento representativo para que se faça a compreensão dos fatos científicos. A realidade, por sua vez, é totalmente vedada ao sujeito epistêmico. A relação entre sujeito e objeto se perde em prol de uma via de mão única, onde não há interpenetração do universo empírico sob os fatos científicos. De outra forma, a palavra possui plena autonomia frente a seu referente real - a ciência torna-se um ambiente exclusivamente discursivo, onde os jogos de palavras se traduzem em formas de vida, e essas, na prática científica (proferir discursos legitimamente reconhecidos pela sociedade e aceitos pelos pares acadêmicos). A ciência, nesse sentido, funde-se gradativamente com o mundo da vida, e a compreensão da sua dinâmica existencial é de fundamental importância para a explicação da origem dos fatos científicos, construídos pelos homens que vivem em um ambiente histórico e societário transitório. Trata-se, portanto, de uma forma de explicação influenciada por teses pós-estruturalistas, particularmente quando se observa a relação entre a palavra e o objeto, situados em pólos distintos e, às vezes, completamente isolados um do outro. 
A SCCi desdobra-se em pelo menos cinco correntes, as quais, de maneira conjunta, constituem a tradição sociológica que busca explicar e compreender a ciência e o seu pensamento enquanto uma prática socialmente construída. Uma das principais escolas desta tradição, fundamental para pensarmos na sua disseminação mundial, é o chamado Programa Forte em Sociologia do Conhecimento Científico. Associado ao Science Studies Unit da Universidade de Edimburgo, na Escócia, e ao Science Studies Unit da Universidade de Bath, o Programa Forte possui como principais referências os estudos de David Bloor, Harry Collins e Michael Collins.

A fundamentação epistemológica da SCCi, ou ao menos uma tentativa de realização de tal tarefa, está contida no trabalho de David Bloor (1991), Knowledge and social imagery. Quatro são os critérios que fundamentariam teoricamente o chamado Programa Forte: i) a causalidade, ii) a imparcialidade, iii) a simetria e iv) a reflexividade (Bloor, 1991). Esses quatro princípios buscam dar unidade à Nova Sociologia da Ciência (SCCi), ao mesmo tempo em que tentam negar e criticar os pressupostos teóricos que, de certa forma, fundamentavam os trabalhos anteriormente realizados. Trata-se de um aprofundamento da vertente kuhniana de pensamento, que aqui surge na forma de imperativos teóricos e epistemológicos.

Diferentemente da escola positivista e neo-positivista, a gênese dos fatos científicos não mais é buscada na lógica de reprodução do conhecimento científico, onde uma forma particular de seleção "darwinista" atuaria como meio de aperfeiçoamento do saber sobre os fenômenos físicos (um mecanismo imanente à própria ciência). Se, para Khun, a comunidade científica surge como protagonista dos processos de revolução científica, para a SCCi, a comunidade científica não somente é protagonista da produção dos fatos científicos, mas, antes, ela é a escultora de uma forma quase que fictícia de realidade empírica, vedada ao homem. A comunidade científica, portanto, seria responsável pela construção dos 
fatos científicos. A prática científica, desenvolvida por uma comunidade, ainda seria interpenetrada pelo universo social de sua época. As barreiras entre o científico e o não-científico são fundamentalmente superadas. Finalmente, a ciência ganha ares de atividade culturalmente determinada. Sob os quatro princípios, busca-se normatizar o raciocínio da nova sociologia da ciência, premissas que foram constantemente debatidas na escola de Edimburgo, e nos trabalhos de Harry Collins e Trevor Pinch (2003) e de Collins e Evans (2002).

O princípio da causalidade, como o seu objetivo central, canalizaria os olhares para o estudo dos fenômenos sócio-cognitivos extra-científicos (de ordem psicológica, psicossocial, cultural, econômica e social), que condicionariam o conhecimento científico, construído no interior da comunidade científica. O princípio de imparcialidade, por sua vez, buscaria aperfeiçoar o pressuposto da neutralidade axiológica sob a lógica de uma ciência construída através de fatores sócio-cognitivos diversos, localizados dentro e fora do mundo científico. O segundo princípio volta-se para o estudo da dinâmica científica, entendendo-a como um universo exclusivamente sociológico que abrangeria tanto a análise de teses científicas de sucesso quanto das teses científicas fracassadas (diferentemente dos estudos que somente tomam como objeto de pesquisa as teorias representativas da realidade). No princípio da simetria, tanto o erro quanto o sucesso passam a ter o mesmo fundamento empírico explicativo, dando complementaridade ao princípio de imparcialidade. Em outras palavras, tanto o erro quanto o sucesso de uma lei ou axioma seriam explicados por fatores sociais transcendentes, ou seja, o sucesso deve ser explicado tomando-se como unidade empírica o ambiente social e suas formas de organização, diferentemente do tradicionalmente proposto, onde somente o erro resultaria da interferência de fatores sociais. O princípio da reflexividade, finalmente, busca atribuir à ciência social os mesmos condicionantes transcendentes 
observados nas ciências da natureza, ou seja, atribui a própria sociologia do conhecimento científico a lógica da causalidade, da imparcialidade e da simetria. De forma latente, esses quatro princípios já estariam presentes no trabalho de Thomas S. Kuhn sobre a origem das revoluções científicas. O intuito, realmente, é o de dar unidade aos pressupostos de Kuhn, colocandoos em tela de forma explícita e, de certa forma, objetivamente, sob a égide de um método estático e universal.

Embora possuam esses quatro princípios como uma espécie de núcleo teórico, outras variações podem ser encontradas na SCCi. Estas variações seriam tanto de cunho metodológico quanto de caráter teórico. Nesta perspectiva, podemos classificar os trabalhos desenvolvidos pelos autores ligados a esta tradição de pensamento de acordo com os principais critérios analíticos adotados para o estudo do conhecimento científico na SCCi. Sob tal critério classificatório, quatro vertentes ou subáreas podem ser facilmente identificadas: i) o construtivismo social, ii) o relativismo social, iii) a análise do discurso e iv) o modelo de interesse. Um mesmo autor, todavia, poderá associar-se a mais de uma subárea da SCCi, dificultando-se, assim, a sua classificação sob um critério único e objetivo. Embora essa múltipla associação possa ser um recurso adotado por certos autores, podemos compreendê-la como mero reflexo da carência teórica que caracterizaria a área (ZUCKERMAN, 1988).

Apesar da unidade epistemológica buscada pelo Programa Forte ter resultado na elaboração de quatro princípios que, de maneira geral, objetivam normatizar a vertente kuhniana de análise, ao atribuir um papel efetivo para a comunidade científica no que diz respeito à construção dos fatos científicos, os estudos desenvolvidos pela SCCi, quase que em sua totalidade, não demonstraram, objetiva e empiricamente, a ligação efetiva entre os contornos da sociedade e a morfologia dos fatos científicos desenvolvidos. Com isso, os trabalhos estão muito mais próximos 
de análises de caráter especulativo do que propriamente de trabalhos de demonstração e de confirmação dos quatro princípios que canalizam os estudos da SCCi. Em decorrência desses fatores, são várias as críticas direcionadas aos trabalhos da $\mathrm{SCCi}$, especialmente àqueles que partem do estudo das chamadas controvérsias científicas, que desde a década de oitenta do século passado somam grande número de exemplares.

Dois extremos dividem a sociologia do conhecimento científico. De um lado, observam-se trabalhos voltados para o estudo e para a análise das influências sociais que condicionariam a esfera científica (de um ponto de vista macrossociológico); de outro, estudos dos fenômenos que influenciariam diretamente a construção social dos fatos científicos (sob um ponto de vista microssociológico). Em meio ao processo de institucionalização efetiva da área, observa-se o que pode ser qualificado como um período de transição entre a Sociologia da Ciência e a Sociologia do Conhecimento Científico. Nessa fase transitória, o objetivo das pesquisas era o de observar os elementos estruturais da atividade científica, como, por exemplo, os estudos que buscavam: i) compreender os processos de mudança de caráter teórico na ciência e de que maneira esses fatores se relacionavam com os modelos propostos por Thomas S. Khun, Imre Lakatos (1999) e Karl R. Popper (2002); ii) a análise das descontinuidades no desenvolvimento dos fatos e da instituição científica, incluindo as formas de resistência à inovação e à falsificação de teorias tradicionalmente aceitas pela comunidade científica; iii) o estudo das fontes sócio-culturais e cognitivas que estariam na base do reduzido interesse no desenvolvimento de pesquisas científicas em determinadas áreas e sobre determinados problemas; iv) a análise da estrutura cognitiva da ciência, incluindo-se os esforços para mensurar a extensão do consenso, da codificação teórica e dos seus efeitos sobre a esfera científica; v) a comparação entre a taxa de crescimento do conhecimento em determinadas áreas científicas e o aumento ou a redução das fontes de 
financiamento e de capital investido; e vi) a expansão e o declínio de certas especialidades científicas (ZUCKERMAN, 1989).

As fronteiras analíticas entre os trabalhos desenvolvidos são assaz tênues, explicitando a porosidade entre as diferentes abordagens. Os construtivistas e os relativistas, por exemplo, estão muito próximos da chamada antropologia da ciência, particularmente quando o foco é a utilização do método de pesquisa, de caráter etnográfico e geralmente desenvolvido no interior de laboratórios de pesquisa científica. O construtivismo, ainda, teria outra subdivisão, denominada de antropologia simétrica, cujo principal expoente é o francês Bruno Latour (2001a e 2000). O construtivismo latouriano caracteriza-se pela radicalização do critério de simetria cunhado por David Bloor. Para Latour (2001b), não bastaria apenas aplicar o princípio da simetria sobre o erro e o sucesso acerca dos fatos científicos, sendo necessário expandi-lo para a relação entre sujeito/objeto, ou seja, para a relação entre humanos e não-humanos. Trata-se da chamada teoria do actante em rede (Actant-Network Theory), trabalhada pelo autor por vários anos. ${ }^{9} \mathrm{O}$ conhecimento científico, no entanto, seria localmente situado, ocasional e circunstancial..$^{10}$ Por sua vez, a análise do discurso possui fortes influências

9 Os estudos construtivistas tomam o laboratório como o espaço privilegiado para a análise. De acordo com os autores que seguem esta tradição, é no laboratório que se inicia a construção social dos fatos científicos, sendo possível, desta forma, apreendê-los ainda durante a sua fase de construção. Possui como principal característica a utilização do método etnográfico, a partir do qual busca-se observar não somente a construção do fato, mas também a sua construção interpretativa. Latour e Woolgar (1979) e Karin Knorr-Cetina (2000) são os principais expoentes desta tradição. Para os dois autores, a natureza e a realidade seriam dados secundários, sendo, portanto, produtos da construção realizada no ambiente de laboratório. Neste sentido, a natureza não se impõe sobre o trabalho no interior do laboratório, sendo produto do trabalho científico.

10 Knorr-Cetina (2000), em um de seus trabalhos, por exemplo, analisa a constituição de dois laboratórios distintos, um de física e o outro de biologia molecular. De acordo com a autora, apesar de ambos os espaços atenderem à prática científica, os dois laboratórios possuem finalidades diferentes: um produz a realidade e o outro a manipula. As diferentes interações entre os agentes científicos e não-científicos, bem como o processo de persuasão e de convencimen- 
da etnometodologia, desenvolvida nos Estados Unidos durante a década de 60 do último século. Fortemente influenciada pela sociologia do conhecimento de Berger e Luckmann (1983), parte do princípio de que a realidade é socialmente construída em meio à vida cotidiana, o chamado mundo da vida, sendo Harold Garfinkel (1967), professor de sociologia da Universidade da Califórnia, o seu principal expoente. Finalmente, os trabalhos elaborados a partir do modelo de interesse objetivavam estudar a influência de certas variáveis sociais sob a atividade científica e o seu conhecimento em particular, especialmente, i) classe social, ii) religião, iii) preferência política, entre outras. De maneira geral, trata-se de analisar a experimentação como um elemento contingente, ou seja, os efeitos dos interesses sócio-cognitivos sobre o conhecimento científico. ${ }^{11}$

to, a fim de disseminar a legitimidade de uma teoria, são tratados pela autora através do conceito de arena-transepistêmica. Para Latour e Woolgar (1979), há um procedimento similar de convencimento e de persuasão, em que os interesses controversos dos agentes são estabilizados e canalizados para um objetivo comum: o conceito de arena dá lugar ao conceito de translação. Independentemente do léxico e do sentido adotado, a noção de negociação é fundamental para a interpretação do trabalho de ambos os autores, pois a ciência também seria feita no plano do discurso, sendo que a realidade e a natureza derivam em grande parte deste discurso retórico que busca aliciar os agentes e convencê-los da relevância de determinados fatos.

11 Entre os trabalhos que seguiram esta abordagem de análise, podemos citar o estudo elaborado por Mackenzie (1981) sobre o desenvolvimento da estatística durante entre os séculos XIX e XX, na Inglaterra. De acordo com a argumentação deste autor, a eugenia e o controle das qualidades hereditárias eram debatidos no interior da classe média da época, não somente com vistas à criação de políticas públicas e à especialização profissional, mas também como um meio privilegiado para a legitimação da superioridade biológica de um determinado segmento da sociedade sobre outro. Nesta perspectiva, Mackenzie observa a influência exercida por esses fatores sobre a constituição da teoria estatística, desenvolvida por três pesquisadores da época, Galton, Pearson e Fisher, tomando-os como protagonistas do desenvolvimento da disciplina e, ao mesmo tempo, como uma forma para a justificação do interesse destes cientistas na comprovação da diferenciação eugênica. Outro importante expoente desta tradição é Pickering (1984), autor que elabora um estudo sobre os condicionantes sociais que atuariam sobre a interpretação dos fenômenos científicos na física, exercidos pelo interesse profissional. Analisa, para tal, as controvérsias sobre a chamada partícula "J-psi" e os interesses sociais que influenciaram a sua interpretação no ambiente de laboratório, partindo do estudo de uma controvérsia científica. 
Finalmente, apesar das inúmeras diferenças entre as abordagens analíticas, praticamente todas apresentam como aspecto comum o fato de que a ciência e a tecnociência são, realmente, construções sociais. Apresentadas enquanto reflexo de seu tempo e do local de pesquisa, a gênese dos fatos científicos, isto é, das leis e axiomas, encontra-se diretamente associada à sociedade. O pensamento socialmente condicionado do início de século é, assim, gradativamente substituído por objetos materiais e imateriais cuja construção é buscada através da realização de micro-análises sociológicas voltadas para a associação entre a ciência, o mundo cotidiano e a dinâmica social existente no interior de um laboratório, bem como todo o conhecimento tácito que possa transitar no interior desse ambiente.

\section{Conclusão}

Há aproximadamente um século que as Ciências Sociais, em especial a Sociologia, tem se dedicado ao estudo crítico da atividade científica, sobretudo no que se refere à sua dinâmica social, à sua estrutura e aos seus possíveis condicionantes extra-cognitivos. Em um mundo onde cada vez mais a racionalidade científica ocidental exerce papel fundamental, parece caber ao sociólogo desnaturalizá-la no que diz respeito à sua disseminação despolitizada, afirmando que, por detrás do pressuposto de neutralidade axiológica, há um belo universo sociológico, dotado de valores e de tradições, cujas faces demonstrariam a grande porosidade entre as fronteiras do científico e do não-científico, ou seja, entre o universal e o particular.

Florestan Fernandes (1976), ao refletir sobre a prática de pesquisa do cientista social e de seu protagonismo no mundo, afirmou que, além de cientista, o sociólogo também é um cidadão. Acreditamos que essa mesma afirmação sirva para sintetizar e para dar unidade ao debate proposto neste artigo, pois afinal, e independentemente de qual seja a tra- 
dição de pensamento (a SCo, SCi e a SCCi), parece existir a necessidade de que tanto a ciência quanto o cientista sejam compreendidos, respectivamente, como instituição social e como sujeito político, inseridos em determinados contextos sociais.

Embora existam importantes distinções entre as três tradições de pensamento aqui debatidas, podemos defender que há, sim, interpenetração entre os seus argumentos. Independentemente da tradição, observa-se um certo tom pessimista, particularmente quando buscava-se atribuir à ciência e à razão uma função cultural emancipatória, como se elas pudessem solucionar objetivamente todos os males do mundo moderno. A ciência, nesse universo, parece corresponder perfeitamente a interesses difusos, cuja variabilidade argumentativa não é, sob nenhum aspecto, de caráter aleatório. Tanto a Sociologia do Conhecimento quanto a Sociologia da Ciência e a Sociologia do Conhecimento Científico partem de um princípio geral, que é o do ceticismo sobre a possibilidade de que a ciência seja norteada de forma absolutamente neutra, pois, antes de tudo, ela responde às variações sociais de espaço e de tempo, categorias estas já condicionadas pelos aspectos sociais. Nem mesmo as leis científicas estariam livres de tal condicionamento. No entanto, a passagem de uma tradição a outra acarretou perdas quanto à originalidade dos fundamentos empíricos e, sobretudo, dos fundamentos teórico-epistemológicos. Isso é facilmente verificável quando se observa a perda de profundidade de algumas análises contemporâneas da SCCi, quase que automatizadas, pouco requintadas e com reduzido nível de erudição, voltadas para a comprovação empírica direta de que a gênese de todos os fatos científicos seriam, na verdade, construídos socialmente.

Por fim, a contribuição do pensamento sociológico, que tomou para si a ciência enquanto objeto de pesquisa, não somente consolidou um novo campo crítico de reflexões como, também, possibilitou a emergência 
de novas maneiras de se compreender a ciência, tornando-a um produto do universo social. De Karl Mannheim a Robert K. Merton, de Thomas S. Kuhn à Nova Sociologia da Ciência de David Bloor, importantes lições foram aprendidas e, aos poucos, o debate modificou a forma de olharmos a atividade científica. O amor intelectual, do qual nos falava Albert Einstein, como um meio inteligente e quase que literário para explicar a lógica da descoberta científica, cada vez mais faz sentido frente ao olhar do sociólogo, de tal forma que, atualmente, nos deparamos com novas formas de se olhar o universo científico, suas dinâmicas, contradições e conflitos, considerando-se suas variações sociais e o estilo de pensamento de uma época. Mudanças essenciais essas que, portanto, serviram para romper com o senso comum acadêmico que mineralizava e naturalizava certos argumentos em meio ao fazer científico contemporâneo.

\section{Sociological looks on Science in the twentieth century: changes and continuities}

\section{Abstract}

The article examines, in two different moments, the major sociological approaches to science in the twentieth century: the Sociology of Knowledge, the Sociology of Science and the Sociology of Scientific Knowledge. In the first topic, Karl Mannheim's and Robert King Merton's sociological arguments are summarized. We support that the interpretation of Mannheim's work must be recognized as an epistemological prerequisite to the development of Merton's Sociology of Science. Adapted by Merton, Mannheim's sociological metatheory appears in Merton through a functional structuralism approach, associated with a middle range theory. In the second moment, we summarize Thomas Kuhn's arguments for, subsequently, examining the Sociology of Scientific Knowledge as a constructive appreciation to mertonian tradition of thought. The study of the logic principles of David Bloor's Sociology of Scientific Knowledge as well as the investigation of the tradition of thought started in University of Edinburgh, Scotland, was the ele- 
mentary focus of this topic. Finally, the major characteristics of each tradition are elucidated, searching for changes and continuities that enable the development of the sociological approach on scientific activity since its classical genesis until the contemporary studies.

Keywords: Epistemology. Sociological Theory. Sociology of Knowledge. Sociology of Science. Sociology of Scientific Knowledge.

\section{Referências}

BERGER, Peter; LUCKMANN, Thomas. A construção social da realidade: tratado de sociologia do conhecimento. 5 ed. Petrópolis/RJ: Vozes, 1983.

BOURDIEU, Pierre. Science de la science et reflexivite: cours du college de France. Paris: Raisons d'agir, 2001.

BLOOR, David. Knowledge and social imagery. Chicago: University of Chicago Press, 1991.

COLLINS, Harry; PINCH, Trevor. O Golem: o que você deveria saber sobre ciência. São Paulo: UNESP, 2003.

. EVANS, Robert. The third wave of science studies: studies of expertise and experience. Social Studies of Science, 32/2, p. 235-296, april 2002.

DILTHEY, Wilhelm. Crítica de la razón histórica. Barcelona: Península, 1986.

FERNANDES, Florestan. A sociologia numa era de revolução. Rio de Janeiro: Zahar, 1976.

FLECK, Ludwik. La genesis y el desarollo de un hecho científico. Madrid: Alianza Universidad, 1986.

GARFINKEL, Harold. Studies in ethnomethodology. New Jersey: Prentice Hal, 1967.

JAY, Martin. Permanent exiles: essays on the intellectual migration from Germany to America. New York: Columbia University Press, 1986.

KHUN, Thomas S. A estrutura das revoluções científicas. São Paulo: Perspectiva, 2006.

KNORR-CETINA, Karin. Epistemic cultures: how the science make knowledge. Cambridge: Harvard University Press, 2000.

LAKATOS, Imre. Falsificação e metodologia dos programas de investigação. Portugal: Edições 70, 1999. 
LATOUR, Bruno. A Esperança de Pandora. Bauru-SP: EDUSC, 2001a.

. Nous n'avos jamais ete modernes: essai d'anthropologie symetrique. Paris: Editions La Decouverte \& Syros, 2001b.

. Ciência em Ação: como seguir cientistas e engenheiros sociedade afora. São Paulo: Editora Unesp, 2000.

. WOOLGAR, Steve. Laboratory life: the social construction of scientific facts. Bervely Hills: CA, Sage, 1979.

MANNHEIM, Karl. Ideologia e Utopia. Rio de Janeiro: Zahar, 1976.

- MERTON, Robert K.; MILLS, Charles Wright. Sociologia do conhecimento. Antonio Carlos Bertelli; Moacir G. Soares Palmeira; Otavio Guilherme Velho (Orgs.). Rio de Janeiro: Jorge Zahar Editor, 1974.

MACKENZIE, Donald A. Statistics in Britain, 1865-1930: the social construction of scientific knowledge Edinburgh: University of edinburgh Press, 1981.

MERTON, Robert K. Sociologia: teoria e estrutura. Miguel Maillet (Trad.). São Paulo: Mestre Jou, 1970.

. Science, technology and society in seventeenth century England. New York: Howard Fertig, 1970.

MARX, Karl. ENGELS, Friedrich. A ideologia alemã. São Paulo: Civilização Brasileira, 2007a.

- O manifesto do partido comunista. São Paulo: Paz e Terra, 2007b.

PARSONS, Talcott. The social system. London: Routledge and Kegan Paul, 1951.

PICKERING, Andrew. Constructing Quarks: a sociological history of particle physics. Chicago: University of Chicago Press, 1984.

POPPER, Karl R. A Lógica da pesquisa científica. São Paulo: Ed. Cultrix, 2002.

SZTOMPKA, Piotr. Introduction. In: MERTON, Robert; SZTOMPKA, Piotr. On social science and structure. Chicago: Chicago University Press, 1996.

ZUCKERMAN, Harriet. The sociology of science. In: SMELSER, Neil J. (Ed.). Handbook of sociology. Califórnia: Sage Publications Inc., 1988.

Recebido: 06/04/2009

Aceite final: 19/06/2009 